\title{
VIRTUALIZAÇÃO DA MEMÓRIA NA CIÊNCIA DA INFORMAÇÃO BRASILEIRA
}

\author{
MEMORY VIRTUALIZATION IN THE BRAZILIAN \\ INFORMATION SCIENCE
}

\author{
Luciana Milania \\ Luis Fernando Herbert Massoni ${ }^{b}$ \\ Valdir Jose Morigic
}

\begin{abstract}
RESUMO
Introdução: originado de reflexões acerca da utilização de termos e conceitos distintos atribuídos à memória em ambientes virtuais e digitais, observa que a memória vem sendo reconfigurada por novas práticas socioculturais que a sociedade desenvolve em seus processos comunicativos, em um fluxo informacional incessante que desterritorializa e ressignifica a memória. Objetivo: compreender como é estudada a virtualização da memória na Ciência da Informação brasileira. Metodologia: estudo qualitativo e bibliográfico na Base de Dados Referenciais de Artigos de Periódicos em Ciência da Informação. Identifica e mapeia os autores e os termos, expressões e definições utilizados por eles ao se referirem à memória em ambientes virtuais e digitais. Analisa a relação entre os termos e os conceitos, de modo a evidenciar como os autores se apropriam desses conceitos. Resultados: dentre os termos, destacam-se memória digital, patrimônio digital e memória virtual. Conclusões: mesmo apresentando incongruências conceituais, as discussões pairam em torno dos desafios de se preservar as memórias digitais e virtuais.
\end{abstract}

Descritores: Ciência da Informação. Virtualização da Memória. Memória Digital. Memória Virtual. Patrimônio Digital.

\section{INTRODUÇÃO}

Da oralidade à escrita e da escrita à informática, a importância do estudo

\footnotetext{
a Mestranda em Ciência da Informação (PPGCIN/FABICO/UFRGS). Bacharel em Biblioteconomia pela Universidade Federal do Rio Grande do Sul (UFRGS). E-mail: lu1000ani@gmail.com.

b Doutorando em Comunicação e Informação pelo Programa de Pós-Graduação em Comunicação e Informação da Universidade Federal do Rio Grande do Sul (PPGCOM/UFRGS). Email: luisfernandomassoni@gmail.com.

c Doutor em Sociologia (USP) e pós-doutor em Memória Social (UNIRIO). Professor titular da FABICO/UFRGS e dos Programas de Pós-graduação em Comunicação (PPGCOM), Ciência da Informação (PPGCIN) e Museologia e Patrimônio (PPGMUSPA). E-mail: valdir.morigi@gmail.com.
} 
da memória no mundo contemporâneo deve-se às mudanças em relação às formas de armazenamento e nos suportes de informação, cada vez mais mediadas pelas Tecnologias de Informação e Comunicação (TIC). As memórias precisam estar alicerçadas em alguma superfície, física ou não, e "guardadas" pelo desejo de não esquecimento, de perpetuação das lembranças, em um esforço de confinamento do tempo, que insiste em passar, alheio às nossas vontades. Seja a partir de uma abordagem filosófica (virtual) ou cibernética (digital), é necessário repensar as formas contemporâneas de lidar com a memória, advindas das TIC. Isso porque a memória vem sendo reconfigurada por novas práticas socioculturais que a sociedade desenvolve em seus processos comunicativos, em um fluxo informacional incessante que desterritorializa e ressignifica a memória. Tendo em vista esses aspectos, esta pesquisa objetiva compreender como é estudada a virtualização da memória na Ciência da Informação brasileira.

A partir de algumas premissas básicas, percebe-se que já existe a preocupação de autores da Ciência da Informação na conceituação utilizada nos estudos que envolvem memória em ambientes virtuais. O surgimento de novos termos, como "memória virtual", "memória digital", "patrimônio digital" e "memória em rede" nas concepções epistemológicas e teóricas relacionadas à temática da virtualização da memória provoca uma série de reflexões acerca da utilização de termos e conceitos distintos atribuídos à memória em ambientes virtuais. Entretanto, nem sempre a utilização de um mesmo termo está atrelada à mesma concepção por parte dos autores, pois um mesmo termo, às vezes, se refere a conceitos diferentes e vice-versa, dependendo da perspectiva adotada por cada autor. A própria diferenciação entre "virtual" e "digital" é tema de discussões entre autores. Assim sendo, a partir da sistematização de alguns termos e definições e da análise dos seus usos em diferentes contextos de pesquisa, pode-se evidenciar de que modo os autores da área estão se apropriando e desenvolvendo os estudos sobre memória em ambientes virtuais.

Metodologicamente, trata-se de um estudo qualitativo e bibliográfico que, utilizando-se da Base de Dados Referenciais de Artigos de Periódicos em Ciência da Informação (BRAPCl), mapeia os autores e os conceitos relacionados 
à memória e sua virtualização na literatura científica do campo da Ciência da Informação brasileira. Para a formação do corpus de análise, buscou termos relacionados à memória em ambientes virtuais, previamente selecionados e estruturados no referencial teórico existente, com recorte temporal estabelecido de 2009-2018. Desta forma, o estudo proposto nesta pesquisa visa preencher uma lacuna no processo de construção conceitual do campo de memória e destarte contribuir para os avanços epistemológicos nas pesquisas acerca do tema na Ciência da Informação.

\section{MEMÓRIA E VIRTUALIZAÇÃO: TERMOS E CONCEITOS BASILARES}

A memória é um fenômeno estudado por diversas áreas do saber, configurando-se como um tema transdisciplinar, sendo a transdisciplinaridade uma das proposições do campo de pesquisa em memória social (GONDAR, 2016), que possui uma importância ética e política perante a história de nossa sociedade. Quando se pensa em memória, talvez o primeiro conceito correlato a emergir em nossas reflexões seja a lembrança - a memória é entendida por muitos como um conjunto de lembranças. Entretanto, memória é um fenômeno igualmente marcado pelo esquecimento, às vezes compreendido como um processo de não-memória, apagamento, inexistência de lembranças, o que é tido como péssimo, especialmente em uma sociedade que deseja preservar tudo.

A possibilidade de desaparecimento de memórias desperta a ideia de "[...] que não há memória espontânea, que é preciso criar arquivos" (NORA, 1993, p. 13), lugares de memória onde se ancoram as referências, os vestígios, as reminiscências de memórias. Lugares como bibliotecas, museus, monumentos, edificações, espaços urbanos, documentos e objetos que legitimam os saberes, as crenças, os costumes, as tradições, as experiências e as histórias dos sujeitos. Para o autor, a memória é a vida e as experiências interpretadas em processos de lembrança e de esquecimento, que independem das alterações permeadas pelas vivências.

Localizar e reconstruir lembranças são atos contínuos que ocorrem através dos contextos sociais (linguagem, espaço, tempo, família, religião, 
classes sociais, tradições), cunhados e denominados por Halbwachs (1952) de quadros sociais, quando, então, a memória dita individual emerge na dimensão coletiva. Para o autor, a memória coletiva se constrói nas relações com os grupos sociais, nas interações com os outros sujeitos. A memória coletiva carrega o sentido de partilha, de pertencimento, de uma intenção de memória, em que as lembranças não coexistem isoladamente e vão "[...] além das fronteiras que as preservam" (GONDAR, 2016, p. 34). Lembranças comuns que, segundo Halbwachs (1990), são evocadas continuamente e transpostas em percepções diferenciadas em cada indivíduo em um grupo ou sociedade. Essa articulação dinamizada pelas relações e as lembranças pessoais modela a apropriação da memória, que Casalegno (2006) interpreta como inter-relações individuais baseadas em "quadros de compreensão".

Os processos memorialísticos não poderiam ficar indiferentes às nossas transformações socioculturais. Com a proliferação dos suportes computacionais, surgem os ambientes virtuais, espaços intangíveis visualizados em uma tela e representados por registros de textos, imagens, sons, movimentos, etc. $O$ sujeito, a informação e a coletividade se inserem na virtualidade, desterritorializando as memórias, "[...] uma espécie de desengate os separa do espaço físico ou geográfico ordinários e da temporalidade do relógio e do calendário [...] a virtualização Ihes fez tomar a tangente" (LÉVY, 2003, p. 21). Através do virtual, a memória é exteriorizada, configurando novas formas de registro memorial.

A transformação nas formas de registro, a partir da escrita, é evidenciada por Nora (1993, p. 14) como um contexto em que "[...] menos a memória é vivida do interior, mais ela tem necessidade de suportes exteriores e de referências tangíveis de uma existência que só vive através delas". Concernente a esta visão, Lévy (2003) refere-se às TIC como prolongamento da memória, potencializada pela comunicação. A contemporaneidade é marcada pela transformação dos suportes em que se inscreve a memória. Essas novas modalidades engendram a facilidade do acesso à informação e a consequente preocupação com a preservação do presente e do passado, hoje de interesse dos indivíduos e não apenas das instituições oficiais, como uma tentativa de 
evitar o desaparecimento da memória e mantê-la no virtual, numa concepção de atualidade.

Diante de uma sociedade produtora, disseminadora e usuária de conteúdos armazenados em ambientes virtuais, em uma velocidade e efemeridade inerentes à sua natureza, os registros não são apenas representações, dada a permanente possibilidade de construção e reconstrução das memórias. As informações e os objetos são criados, circulam, são assimilados e recriados de acordo com o modelo clássico do círculo da informação, mas a percepção humana não acompanha esse trajeto e seus movimentos em toda sua intensidade (DODEBEI, 2008). Desatrelado ao tempo e ao espaço, o mundo virtual/digital gera novas possibilidades de construção e circulação do conhecimento.

A memória nos ambientes virtuais tem sido objeto de estudo diante desse "[...] impacto do virtual e do digital na construção do conhecimento e a comunicação da informação" (MANGAN, 2010, p. 171). Percebe-se uma alteração no espaço-tempo no contexto eletrônico, em que se desenvolve a memória virtual, que "[...] supõe a existência de suporte digital, ou seja, uma memória digital. Por outro lado, é possível haver registros digitais que seriam uma forma de memória digital, que não configurem uma memória virtual por não estar compartilhada em rede" (MANGAN, 2010, p. 171). Dessa forma, a memória digital é determinada pelo suporte computacional, associada a questões técnicas e às tecnologias de informação, enquanto que uma memória virtual é determinada pela conexão e dispersão da internet, transcendendo o espaço físico, associada também às tecnologias de comunicação.

A memória virtual precisa da memória digital para existir, mas um registro digital somente tem significado com memória coletiva e/ou social ao se tornar virtual. Os novos espaços de memória (virtual) passam a ser repositórios de memória digital cuja informação é socializada através da internet. Embora sejam espaços virtuais, seu conteúdo é real, assim como os sujeitos responsáveis por construir e comunicar as memórias. (MANGAN, 2010, p. 176).

Os ambientes virtuais são formados por espaços virtuais que contêm memórias individuais e coletivas representadas por textos, imagens, sons e qualquer outro objeto informacional, com equivalente ou não no mundo físico. As 
informações ali armazenadas não possuem linearidade e estão sujeitas à reestruturação, sem uma organização cronológica. Segundo Dodebei (2008), novas nomenclaturas surgem ou são reinventadas nestes ambientes, entre eles a do documento:

Ao ingressar no ciberespaço o documento se transforma em recurso informacional e passa a fazer parte do estoque informacional que constitui a memória virtual da web. Assim é que sua nomenclatura muda; de documento para recurso, no caso do acesso, e de documento para objeto informacional, no caso de sua representação digital. (DODEBEI, 2006, n.p).

Com base no conceito de memória nas áreas de Arquivologia, Biblioteconomia e Museologia, pensa-se em memória como "[...] conjunto de informações registradas [..] memória no sentido de armazenagem e preservação dos saberes (conservação), para a posterior recordação por parte da sociedade" (MONTEIRO; CARELLI; PICKLER, 2006, p. 115). As autoras abordam as aproximações e os distanciamentos inerentes à linguagem da memória nos ambientes virtuais, e inferem sobre a capacidade de armazenamento e preservação dos registros a partir do uso da palavra escrita. Da oralidade à escrita, observa-se "como consequência dessa mudança a reformatação da informação em seus contextos de produção, de armazenamento e de recepção" (DODEBEI, 2006, n.p), o que gera um novo olhar sobre estes processos nos ambientes virtuais. Ainda de acordo com Dodebei (2008):

Digitalizar compreende o processo de representar um objeto concreto ou analógico em bits. A imagem digitalizada se transforma em conjuntos de pixels que podem ser compreendidos visualmente pelo olho humano e também por programas de computação. A diferença entre digital e virtual está diretamente vinculada ao processo, no caso do atributo digital, e no meio ou ambiente, no caso do virtual. Podem existir, desta forma, objetos digitalizados que habitam tanto o mundo concreto como o mundo virtual. (DODEBEl, 2008, p. 3).

O termo memória virtual parece associado à digitalização, resultado desse processo. Para Monteiro, Carelli e Pickler (2006), a memória virtual que habita o ciberespaço possui algumas aproximações com a memória das sociedades orais: uso do discurso narrativo, uso de imagens e possibilidades de esquecimento. Entretanto, ela se consolida como uma nova forma de memória, não mais externalizada e preservada em materialidades - um saber em estoque, mas sim como uma memória dinâmica, em favor de um saber em fluxo. 
Diante de novas linguagens, Oliveira (2010) ressalta a importância das criações de caminhos de associações para o acesso às representações nos ambientes virtuais, sendo estas fundamentais para a recuperação da informação. Já Lazzarini, Netto e Souza (2015, p. 24) compreendem o ciberespaço como um lugar de destaque pelas possibilidades de acesso, pois, diante do aparato informacional em meio virtual, gera a necessidade de novos meios de registro e preservação da memória. Em outro viés, Monteiro, Carelli e Pickler (2006) não associam as representações no ciberespaço tanto ao sentido de conservação, como ocorre no mundo físico, e sim às múltiplas possibilidades de produção e contínua transformação.

Para Casalegno (2006, p. 32), que versa em uma visão ecológica, as narrativas têm um papel fundamental na formação da memória coletiva e independem do espaço e do tempo, onde "[...] partilhar uma memória é em um sentido, ter partilhado as experiências vividas em conjunto". Nesses ambientes, a memória é um processo em permanente construção, através da reconstituição de significados e de novas possibilidades de representação do conhecimento e dos saberes. $O$ autor compreende a memória em rede "[...] em uma ótica em que o ciberespaço se superpõe ao espaço, o real e o virtual não repelem nem se opõem, mas dão lugar a uma topografia de lugares ampliada, a fim de coexistir e criar uma nova forma de topologia urbana [...] ambientes transformados em uma verdadeira interface da memória" (2006, p. 23), que armazenam um volume crescente de informações digitais.

O sistema da memória em rede "[...] se inscreve nessa lógica, tentando promover a partilha da memória cotidiana e informal, além de buscar tornar acessível não apenas a memória histórica, formal [...], mas também a memória vivida e interpretada pelos seres humanos" (2006, p. 20). Esta aproximação confere o caráter de memória comunitária, proporcionando um ambiente de partilhas em que a tecnologia potencialize o aparecimento de laços e conexões, que se distanciam do indivíduo e passam a ser representações coletivas, em um constante movimento de reconstrução no ciberespaço. Assim, os ambientes virtuais possibilitam visibilidade e compartilhamentos de bens materiais e imateriais, atribuindo um caráter social à informação - além da socialização, há 
também o caráter de virtualidade:

[...] quando observamos a organização dos bens patrimoniais digitalizados ou criados digitais e que circulam na memória virtual do mundo. Temos aí delineadas algumas complexidades para a construção do sentido e do significado de patrimônio virtual e de patrimônio digital. A primeira delas diz respeito à compreensão de uma extensão conceitual ao que tradicionalmente se nomeia como patrimônio. Os adjetivos virtual e digital, por exemplo, modificam o conceito de patrimônio, especificando-o com propriedades criadas no âmbito da filosofia (Virtual) ou no âmbito da Cibernética (Digital). O conceito de patrimônio sofre também outras transformações produzidas pelas novas dimensões de tempo e de espaço do mundo organizado por redes interligadas de computadores, notadamente em relação aos atributos de acumulação, permanência e integridade. (DODEBEI, 2008, p. 1).

Assim, valida-se o pressuposto de que o ambiente virtual possibilita a transformação do bem patrimonial em objeto informacional. A velocidade e a efemeridade, características do ciberespaço, transformam as memórias em recursos e/ou objetos informacionais representados pela virtualidade imagética, com a informação sendo constantemente construída e reconstruída. Isso permite compreender, seguindo a perspectiva de Dodebei (2008), que as memórias informacionais geridas em ambientes virtuais não são meros bancos ou bases de dados, mas centros de conhecimento, sendo o caráter coletivo o principal atributo responsável por fazer da web um grande centro virtual da memória do mundo.

\section{METODOLOGIA}

A metodologia deste estudo teve como base as informações oriundas de pesquisa exploratória nos textos indexados na BRAPCl. Através da pesquisa bibliográfica, levantou-se os trabalhos publicados por autores no campo da Ciência da Informação brasileira, com a recuperação por palavras-chave. Para a busca, elegeram-se as seguintes palavras-chave: "virtualização da memória", "virtualização AND memória", "memória virtual", "memória AND virtual", "memória digital", "memória AND digital", "patrimônio digital", "patrimônio AND digital", "patrimônio virtual", "patrimônio AND virtual", "memória em rede", "cibermemória" e "memória AND ciberespaço". Além do operador booleano AND, 
também foi aplicado o uso de aspas em algumas palavras-chave, como tentativa de refinar a busca de registros com conteúdo relacionado à memória em ambientes virtuais. Como recorte temporal, a pesquisa bibliográfica foi delimitada inicialmente do ano 2000 a 2018. A coleta ocorreu entre os dias $1^{\circ}$ e 10 de março de 2019, com a pesquisa bibliográfica resultando em 642 registros. O passo subsequente foi a exclusão dos registros duplicados, que resultou na seguinte quantidade de registros: um em virtualização da memória; 44 em memória virtual; 132 em memória digital; 22 em patrimônio virtual; 76 em patrimônio digital; 38 em memória em rede; e 11 em memória $A N D$ ciberespaço, perfazendo um total de 324 registros.

$\mathrm{Na}$ etapa seguinte, houve a classificação da produção científica com base nos dados obtidos relativos ao campo de atuação e país dos autores, como também a identificação de registros repetidos. Nos casos em que não foi possível identificar a área de atuação ou a situação acadêmica dos autores através dos textos, averiguou-se o perfil no Currículo Lattes. A categorização da produção científica recuperada resultou em 34 textos de autores estrangeiros descartados por não atenderem ao critério da pesquisa que estabelecia o recorte por autores brasileiros; 23 textos de autores de outras áreas, desconsiderados por não serem produção de pesquisadores da Ciência da Informação; 97 textos repetidos - textos recuperados em mais de um termo de busca e, em alguns casos, também duplicados em um mesmo termo de busca; e 170 textos de autores da Ciência da Informação brasileira - considerou-se toda a produção científica com no mínimo um autor vinculado à Ciência da Informação ou às áreas de Arquivologia, Biblioteconomia ou Museologia.

Iniciou-se a etapa de leitura técnica dos resumos dos 170 textos produzidos por autores da Ciência da Informação brasileira e observou-se que, através dos resumos, não seriam obtidas informações relativas aos termos e definições e nem qualquer possibilidade de embasamento teórico. Partiu-se, então, para uma nova sistemática, reduzindo-se o recorte temporal para dez anos: 2009 a 2018. Com base nessas premissas, foram descartados 22 textos publicados entre 2000 e 2008, resultando em um corpus de pesquisa formado por 148 produções científicas que foram, então, submetidas à leitura técnica do 
texto completo.

Através da análise do conteúdo do corpus, identificou-se 106 textos que tratavam de temas relacionados à memória em ambientes virtuais, em sua maioria voltados para aspectos de implantação de tecnologias, organização do conhecimento, criação de repositórios digitais e de problemáticas inerentes à preservação digital, que não incluíam definições e nem aproximações vinculadas aos objetivos deste trabalho. Assim sendo, obteve-se 42 textos com abordagem relacionada à temática da memória e virtualização, que contemplam efetivamente termos e definições que contribuem para o mapeamento dos autores que pesquisam virtualização da memória na Ciência da Informação brasileira e a análise das relações entre os termos e as definições nos contextos textuais em que são empregados. Ilustrando os resultados, construiu-se um esquema apresentando os conceitos identificados nos textos, evidenciando as relações associativas entre eles.

\section{MEMÓRIA E VIRTUALIZAÇÃO: TERMOS E CONCEITOS EMERGENTES}

Do total de 42 textos analisados nessa pesquisa, 35 foram publicados em artigos de periódicos e sete foram apresentados nos ENANCIB, verificando-se a atuação de 70 autores em estudos que abordam aspectos relacionados à temática memória e virtualização, vinculados a 25 instituições - 24 nacionais e uma internacional. O Quadro 1 apresenta esses autores e suas respectivas instituições.

Quadro 1 - Autores e Instituições que Estudam Memória e Virtualização.

\begin{tabular}{|l|}
\hline Autores e Instituições \\
\hline Adriana de Buarque de Holanda (UFPE), Amanda Maria de Almeida Nunes (UFPE), \\
Ana Suely Pinho Lopes (UFSM), Anahi Rocha Silva (UNESP), Analaura Corradi \\
(UNAMA), Andréa Doyle (IBICT-UFRJ), Ângela Maria Ferreira de Andrade (UFS), \\
Artur Simões Rozestraten (USP), Augusto César Luiz Britto (UNAMA), Célio Andrade \\
de Santana Júnior (UFPE), Cristine Martins Gomes Gusmão (UFPE), Daniel Flores \\
(UFSM), Diana Marcela Bernal Ramirez (UEL), Diego Salcedo (UFPE), Edna Lúcia \\
da Silva (UFSC), Eliana de Azevedo Marques (USP), Eliane Braga de Oliveira (UnB), \\
Fabiana Conceição Lima Luz (UFS), Fabiano Ferreira de Castro (UFSCar), Fábio \\
Mascarenhas e Silva (UFPE), Fabíola Rubim Silva (UFJF), Gabriela Aparecida da \\
Cunha Yamane (UFSCar), Georgete Medleg Rodrigues (UnB), Henrique Machado \\
dos Santos (UFSM), Igor Pires Lima (Tribunal Federal da Quinta Região), Ilaydiany \\
\hline
\end{tabular}


Oliveira Silva (UFRN), Isa Maria Freire (UFPB), Janaína Cardoso de Mello (UFS), João Fernando Igansi Nunes (UFPel), João Pedro Silva de Albuquerque (UFPE), Jocelaine Rodrigues de Sena (UFRGS), José Luiz Costa Sousa Gonçalves (UFRJ), Josiane Lemos Machiavelli (UFPE), Juliana Cardoso dos Santos (UEL), Juliane Conceição Primon Serres (UFPel), Juliana de Assis (UFRJ), Karen Kahn (UNESP), Letícia Gorri Molina (UEL), Lídia Maria Batista Brandão Toutain (UFBA), Ligia Café (UFSC), Luciana Aparecida de Lima Castilho (USP), Luis Fernando Herbert Massoni (UFRGS), Luísa Maria G. M. Rocha (Instituto de Pesquisas Jardim Botânico Rio de Janeiro), Májory Karoline Fernandes de Oliveira Miranda (UFPE), Marcos Galindo (UFPE), Maria Giovanna Guedes Farias (UFPB), Maria Márcia Crisanto Leão Montijano (UFS), Maria José Vicentini Jorente (UNESP), Marina de Souza Barbosa Ferreira (USP), Marina Gowert dos Reis (UFPel), Marina Leitão Damin (UNIRIO), Marisa de Oliveira Mokarzel (UNAMA), Mirleno Lívio Monteiro de Jesus (UFBA), Moisés Rockembach (Universidade do Porto), Pablo Soledade (UFBA), Paula Wivian Quirino Dos Santos (UFPE), Renata Cardozo Padilha (UFSC), Ricardo Medeiros Pimenta (IBICT-UFRJ), Rodrigo Rabello (IBICT), Rubens Ramos Ferreira (UNIRIO), Sandra de Albuquerque Siebra (UFPE), Sandra Maria Veríssimo Soares (UFPE), Tânia Regina da Rocha Unglaub (UDESC), Tatiana Quadra e Silva Capistrano (Prefeitura Municipal de Florianópolis), Valdir José Morigi (UFRGS), Vânia Mara Alves Lima (USP), Vera Dodebei (UNIRIO), Vera Lucia Marques da Silva (SENAC Francisco Matarazzo), Vildeane da Rocha Borba (UFPE), Virgínia Ferreira da Silva Castro (IBICT).

Fonte: dados da pesquisa.

Entre o mapeamento de autores que versam sobre a temática e a percepção de relações associativas entre os termos e conceitos relativos aos ambientes virtuais e digitais, a leitura dos textos permitiu conhecer a forma com que a memória é abordada na era digital. A seguir, apresentam-se algumas perspectivas identificadas nos diferentes textos.

João Pedro de Albuquerque, Célio de Santana Júnior e Amanda Nunes abordam as redes sociais virtuais como espaços de memória em rede ou também como espaço na internet onde as memórias são construídas coletivamente com a finalidade de acesso e preservação. Para eles, a memória em rede possibilita incessantes fluxos de memória com a contínua criação de novos lugares de memória, a partir da produção e disseminação de conteúdos gerados pelos usuários. Ilaydiany Silva afirma que a era digital difunde a memória digital, um formato de memória constituído pelo conjunto de informações registradas nas redes sociais online e que integra parte da história de uma sociedade. Para a autora, a nova forma de registrar memória na atual era informacional pode transformar as redes sociais em repositórios da memória social. Segundo José Gonçalves e Juliana de Assis, a folksonomia vem se 
consolidando como um importante indexador social para a organização e representação de conteúdos originados no ciberespaço, contribuindo na construção da memória presente na esfera digital (ou memória no contexto digital).

Maria Giovanna Farias e Isa Freire dispõem sobre os processos de coleta, organização, registro e divulgação dos saberes de uma comunidade no ciberespaço como alternativa para os riscos de exclusão informacional. As autoras entendem que esses registros transformam-se em informação disponível na memória virtual mundial. Diego Salcedo e Igor Lima expõem a importância da preservação da memória institucional, inclusive no meio virtual, e o papel do bibliotecário na criação, manutenção e atualização das informações nos espaços de memórias. Entendem que o espaço de memória não deve ser confundido com a memória no ambiente virtual.

No viés da preservação digital e com foco na relação entre memória e contraesquecimento no contexto das tecnologias de informação e comunicação, Mirleno de Jesus, Pablo Soledade e Lídia Toutain abordam questões inerentes às mudanças ocorridas com a transferência do conhecimento do meio analógico para o ciberespaço. Entendem que concerne aos indivíduos e às instituições a responsabilidade na adoção de ações de preservação de acervos digitais, com a organização, registro e armazenamento do conjunto de informações que se constituem na memória digital ou memória nos ambientes virtuais.

Letícia Molina, Juliana dos Santos e Diana Ramirez pautam sobre a integração do homem com as tecnologias comunicacionais, a partir da qual se estabelecem novos formatos de relação com as mídias digitais, promovendo diferenciados processos de apropriação e compartilhamento da informação disponibilizada de forma digital e da memória. As autoras expõem a necessidade de entender o papel da memória na era digital, dado o impacto das mídias na produção e no armazenamento do conhecimento. Já Moisés Rockembach expõe que a memória no contexto atual "não é desmaterializada, mas virtualizada". A transferência, a produção e o armazenamento da informação em um suporte digital não a torna apenas material e, sim, virtual, vinculada a múltiplos processos de construção, reconstrução, interatividade, compartilhamento. Alteram-se os 
modelos vigentes de preservação da memória, embora a preservação ainda não abranja de forma eficaz as complexas representações virtualizadas e constantemente ressignificadas.

Ana Lopes e Daniel Flores abordam questões de preservação da memória digital ou memória dos documentos digitais a longo prazo e com base em um programa relacionado à memória do patrimônio documental mundial. Henrique dos Santos e Daniel Flores apontam a fragilidade dos documentos digitais e os desafios atuais em relação às vulnerabilidades tecnológicas dos registros digitais e a necessidade de conhecê-las, a fim de se evitar lacunas na produção científica ocasionadas pelo desaparecimento ou perda da memória digital. Rodrigo Rabello e Virgínia Castro enfatizam a necessidade de desenvolvimento de critérios e de políticas para a preservação da memória digital, como forma de se estabelecer estruturas condizentes para a guarda e acesso a longo prazo do conhecimento e da memória institucional. Sandra Soares e Marcos Galindo abordam a preocupação com a revolução tecnológica que, na atual cultura digital, impõe a adoção de estratégias eficientes para a guarda e a preservação da memória. Os autores destacam a necessidade de preservação da memória digital como elemento de difusão do estoque cultural.

No contexto de um ambiente de Educação a Distância (EaD), Vildeane Borba, Sandra Siebra, Marcos Galindo, Josiane Machiavelli e Cristine Gusmão refletem sobre o acesso a longo prazo aos recursos digitais e a preservação do patrimônio arquivístico digital que compõe objetos de aprendizagem em ambientes de EaD, compreendendo a memória digital como qualquer informação em meio digital. Seguindo as mesmas discussões e aprofundando mais as questões de políticas de preservação de arquivos, Augusto Britto, Marisa Mokarzel e Analaura Corradi observam que, apesar da digitalização ser massivamente considerada uma forma de preservação, o ciberespaço, por suas características de efemeridade e instantaneidade, não se apresenta como um ambiente estável para a guarda de arquivos.

Os autores corroboram com Monteiro, Carelli e Pickler (2006) sobre a fragilidade da preservação das memórias formadas pelas mensagens originadas das redes de comunicação e das memórias em forma digital, por serem criadas 
sem a preocupação com a longevidade. Entendem que a ausência ou desaparecimento gera o esquecimento digital e, nesse sentido, há o receio do que denominam de "amnésia digital". Com base em outros autores, as memórias oriundas dos arquivos digitais, nesse fenômeno de lembrança-esquecimento, são pensadas como memória artificial, por sua aproximação com a memória "humana".

Aproximando-se da problemática relacionada à amnésia digital e com enfoque na preservação digital de imagens e na preservação integral desses objetos informacionais, Luciana Castilho e Vânia Lima expõem que as tecnologias potencializam a criação e disseminação de informação digital, mas que podem provocar a amnésia digital. Gabriela Yamane e Fabiano de Castro discorrem sobre padrões de descrição para as fotografias digitais ou digitalizadas dispostas em ambientes informacionais digitais, sendo que a representação imagética em meio digital ou eletrônico se constitui em um suporte de recuperação de memória digital, o que promove a reconstrução da memória. Com a mesma postura e focado no contexto arquitetônico, Artur Rozestraten, Vânia Lima, Eliana Marques e Marina Ferreira refletem sobre a necessidade de se estabelecer padrões de representação descritiva dos documentos arquitetônicos físicos e virtuais disponibilizados em um ambiente colaborativo. Os procedimentos de representação e recuperação do patrimônio digital, constituído pelas imagens, visam seu acesso e compartilhamento.

Em outra perspectiva, Adriana de Holanda e Fábio Silva argumentam que a memória eletrônica ou digital traz à pauta a preocupação com o apagamento tanto da memória biológica como da memória artificial que, apesar de externalizada a partir da escrita, evidencia uma possível perda ou destruição da informação. Essas preocupações ficam evidentes em alguns trabalhos como o de Tatiana Capistrano e Tânia Unglaub, para quem a preservação da trajetória histórica de uma instituição perpassa, na atualidade, um memorial virtual, com atributo de memória artificial, por sua criação em um ambiente virtual e a forma como os registros de memória são organizados e preservados.

Já Marcos Galindo observa que os avanços das TIC vêm transformando significamente as formas de armazenamento da memória biológica (humana), 
ampliadas pelas chamadas próteses de memória elaboradas pelos sujeitos. Pelo viés da preservação, a memória digital ou memória em meio digital está condicionada ao valor histórico, econômico e cultural, o que, no entanto, pode afetar o acesso a longo prazo se as instituições não adotarem estratégias e padrões de preservação.

Vera Lúcia da Silva aborda o uso de ferramentas tecnológicas e colaborativas na gestão da informação, auxiliando a implantação de processos educacionais para a aprendizagem no campo da pesquisa. No entanto, traz uma diferenciação conceitual para memória digital: a autora aponta que as informações e os conteúdos podem ser produzidos e arquivados em recursos de armazenamento digital, tais como aplicativos, blocos de notas, gerenciadores de projetos e tarefas, armazenamento em nuvens, etc., compreendidos como memórias digitais, e que permitem a organização da informação e do aprendizado.

Com outro ponto de vista, Georgete Rodrigues e Eliane de Oliveira entendem que, no cenário atual, um mundo virtual intensificado pelas TIC coloca a memória digital - memórias modeladas pelas tecnologias digitais, em movimento, em um constante processo de reconstrução e compartilhamento, em que a memória registrada e armazenada nesse meio (mundo virtual) é recuperada através dos motores de busca, contrapondo-se ao receio de esquecimento, o que, no entanto, acarreta em outras problemáticas relacionadas à memória: o "direito à informação", o "direito ao esquecimento" e o "direito à memória". Percebe-se que as autoras corroboram com a distinção entre memória virtual e memória digital, atrelando a virtualização à reconstrução e ao compartilhamento da memória digital.

Com enfoque nas interfaces de museus virtuais, Rubens Ferreira e Luísa Rocha abordam alguns aspectos da virtualização que, por se apresentar desvinculada de tempo e espaço, é delineada em um sentido de desterritorialização, não estando relacionada tão somente à desmaterialização de objetos. Corroborando com os pressupostos de outros autores, partilham sobre a implantação de linguagens que permitam o acesso universal ao patrimônio digital - considerado como os bens culturais disponibilizados em 
ambiente colaborativo da web, promovendo assim a contínua circulação e difusão.

Para Janaína de Mello, Fabiana Luz, Maria Márcia Montijano e Ângela de Andrade, o uso das tecnologias e dos recursos digitais em museus como meio de preservação da memória na era da globalização e do esquecimento têm demonstrado que a memória social pode ser entendida como patrimônio digital. O cerne e desafio dessa construção social é o processo de virtualização que amplia a guarda e o acesso à memória digital - "fragmentos informacionais na internet", como fonte de preservação dos valores sociais, das heranças, das tradições, das linguagens que se transformam no patrimônio digital mundial. Renata Padilha, Lígia Café e Edna Silva associam o patrimônio digital aos acervos físicos duplicados para o meio digital e o patrimônio virtual relacionam ao patrimônio digital, constituídos de patrimônio imaterial que circula na web. Representado por fragmentos de memória, o patrimônio não deve ser considerado apenas como objeto, mas pelo seu valor como informação, como conhecimento selecionado e compartilhado por determinado grupo.

Maria José Jorente, Anahi Silva e Ricardo Pimenta elencam o uso de plataformas digitais em estudos que visam à visibilidade das memórias em instância digital ou em sua dimensão digital e seus processos de construção, preservação e disseminação. Amplia-se a disponibilização de coleções nesses ambientes, tanto de acervos pessoais como institucionais, fazendo emergir exponencialmente a cultura digital e o patrimônio digital - este representado por bens culturais criados somente no ambiente virtual ou por bens duplicados na representação da web. Os bens duplicados referem-se aos que passam por processo de digitalização. Para as autoras, essa cultura digital tem se configurado como patrimônio digital. Karen Kahn e Maria José Jorente salientam a importância sociocultural do virtual em um contexto de museu virtual, com a disponibilização da coleção virtual de memórias na plataforma, integrando o bem cultural ao ciberespaço.

Com aproximações semelhantes, Marina dos Reis, Juliane Serres e João Nunes refletem sobre os novos processos de significação para os bens culturais ou bens patrimoniais que se constituem no patrimônio cultural digital - 
compreendido como bens culturais materiais e imateriais duplicados digitalmente, protegidos ou não por instituições e estabelecendo práticas colaborativas em meio digital que visibilizam o patrimônio e o acesso à memória coletiva. Os autores também comparam aspectos entre o patrimônio digital e o tradicional de "pedra e cal", apresentando o patrimônio digital e o patrimônio virtual como a representação de bens em circulação no ciberespaço, classificados em bens nascidos eletronicamente $e$ bens duplicados $e$ preservados por processos digitais.

Valdir Morigi, Luis Fernando Massoni e Jocelaine Sena refletem sobre como as redes sociais virtuais suscitam a ideia de lugares de memória. As TIC possibilitam a formação da memória virtual da web ou memória virtual - objetos que se reconstroem em contínuo movimento e que formam o estoque informacional armazenado no ciberespaço. As memórias nos espaços virtuais refletem as memórias compartilhadas e evidenciam aspectos que se assemelham à memória biológica, como o processo lembrar-esquecer.

Luis Fernando Massoni e Valdir Morigi estudam como as redes sociais virtuais moldam as atuais relações dos sujeitos com os lugares e possibilitam a produção e o compartilhamento de experiências em contínua reconstrução de memórias. Os autores entendem que a memória virtual é construída pelas narrativas criadas nos ambientes virtuais e reproduzidas em permanente conexões e reconexões com o passado. Os autores ainda utilizam a expressão memória coletiva virtualizada.

Vera Dodebei, Marina Damin, Valdir Morigi e Luis Fernando Massoni observam os objetos informacionais que constituem os códigos numéricos inscritos nos ambientes virtuais que tornam visível a imaterialidade ou 0 intangível. Nesse sentido, fotos, textos, vídeos e áudios formam a memória e o patrimônio constituído no ambiente virtual e com atributos de mediadores das memórias, possibilitando a representação do patrimônio em meio online e o compartilhamento entre indivíduos e grupos, inserindo a memória em uma dinâmica atualização e modificação dos conteúdos. Os autores referem-se ao ciberespaço como ambiente comunicacional virtual da memória coletiva, onde se manifesta a memória virtual (ou memória no ciberespaço). Debruçando-se 
sobre o estudo das memórias da cidade, compreendem que a memória virtual é constituída pelas representações originadas a partir dos imaginários criados no espaço urbano e em seus elementos.

Vera Dodebei relata a existência de grupos de discussão da memória digital que, apesar de apresentar pautas como a de preservação da memória no ciberespaço, se pelo controle, proteção ou disseminação, ainda não aponta um conceito definitivo para memória digital, sendo esta amplamente entendida como qualquer coisa que circula no ambiente virtual. A intensificação das mídias comunicacionais faz emergir novos valores culturais: o patrimônio digitalizado e o patrimônio nascido digital - objetos informacionais não mais reconhecidos como documento e relacionados ao processo da memória digital.

Vera Dodebei e Andrea Doyle abordam questões relativas aos altos custos dos processos de digitalização de acervos, como recurso de salvaguarda e armazenamento do patrimônio mundial, e apresentam um diálogo entre a memória humana e a memória eletrônica da web/internet, também denominada memória do ciberespaço. As autoras apreendem o ciberespaço como a memória técnica ou memória técnica do ciberespaço, sendo essa memória composta pela rede de sistema computacional (internet) e pela rede de endereços visualizada em uma interface gráfica (web).

Diante da acumulação contínua de informações no ciberespaço, Vera Dodebei destaca aspectos da memória que não se referem às coleções de documentos no ciberespaço, e sim à localização de dados digitais espalhados no ciberespaço. A autora busca compreender os restos memoriais, considerados os dejetos de cunho eletrônico, que a autora denomina restos, ou lixo digital espalhado no ciberespaço, ou também, em outro sentido, os rastros ou lembranças auráticas de vestígios de memória.

A análise dos dados desta pesquisa resultou na identificação de 44 termos e expressões, o que confirma as reflexões iniciais acerca do uso de termos e definições distintos atribuídos à memória em ambientes virtuais e digitais. Nem sempre foi possível identificar os conceitos, visto que nem todos os conceitos são apresentados de forma tão evidente. Pode ser que os autores tenham uma conceituação própria, porém não a definem de maneira objetiva na sua escrita. 
Também é possível observar que os termos não convergem na mesma conceituação entre os autores, refletindo conceitos diferentes, de acordo com o entendimento e a perspectiva adotada por cada autor.

Figura 1 - Esquema de Termos e Expressões Relacionados à Memória e Virtualização.
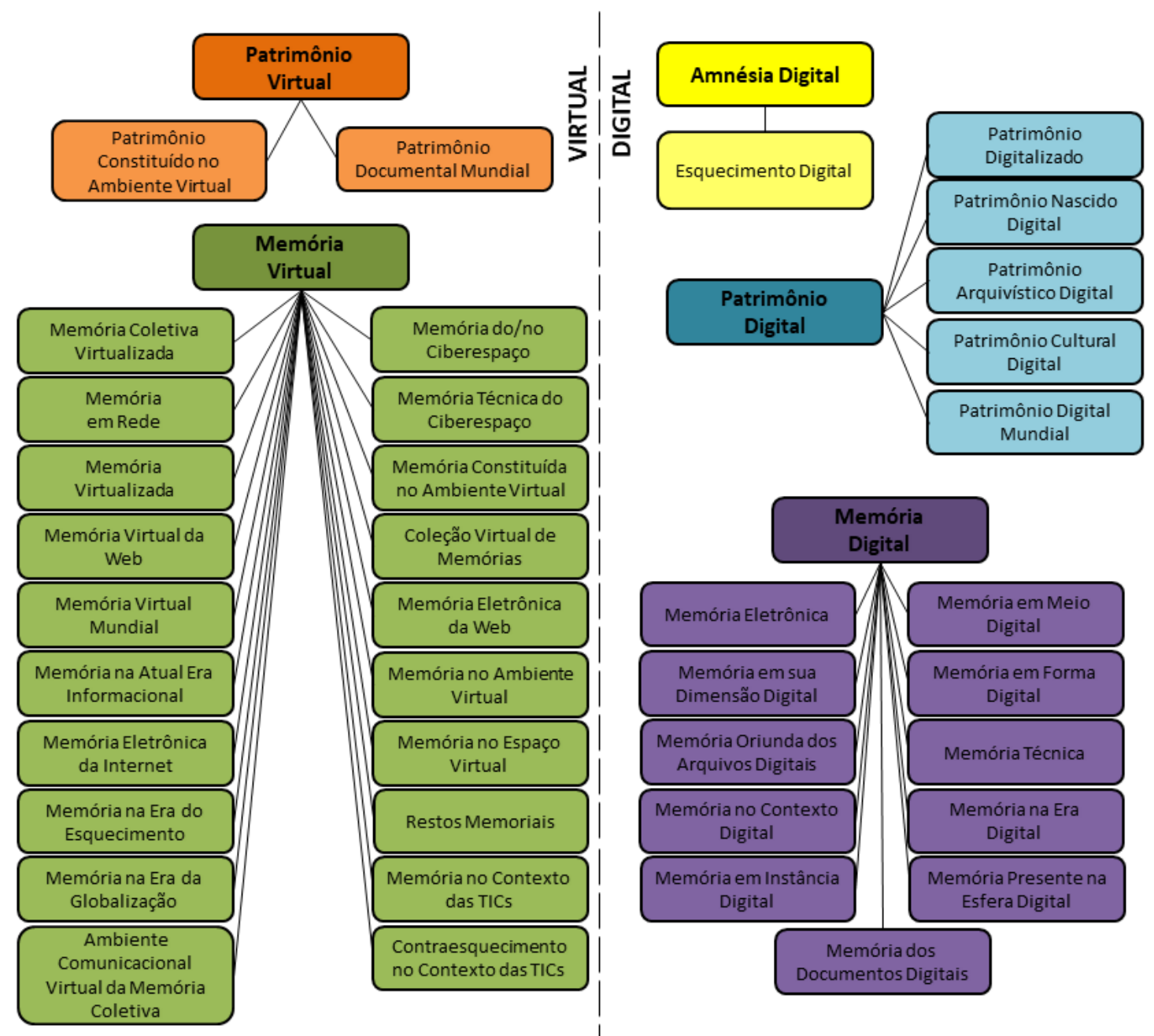

Fonte: dados da pesquisa.

Para uma melhor visualização dos termos e expressões identificados na análise dos textos, foi elaborado um esquema (Figura 1), adotando-se a perspectiva de divisão de organização de acordo com as categorias "virtual" e "digital", considerando a apropriação de alguns autores, com base na proposta conceitual de Mangan (2010), que compreende a memória digital como determinada pelo suporte computacional, associada a questões técnicas e às tecnologias de informação. Compreende-se que há uma diferenciação entre esses conceitos, entretanto, alguns autores consideram os dois como vocábulos 
sinônimos. Assim sendo, por uma questão de organização, optou-se por categorizar dessa maneira, orientando-se pela divisão entre Virtual e Digital e entre Memória e Patrimônio.

Destaca-se o predomínio de ocorrências do termo memória digital, amplamente utilizado e caracterizado por conceituações distintas, assim identificadas, por alguns autores: para Borba, Siebra, Galindo, Machiavelli e Gusmão, como qualquer informação em meio digital; para Dodebei, como qualquer coisa que circula no ambiente virtual; para Rodrigues e Oliveira, memórias modeladas pelas tecnologias digitais; Silva aborda como conjunto de informações registradas nas redes sociais online e que integra parte da história de uma sociedade; para Jesus, Soledade e Toutain, acervos digitais formados por conjuntos de informações na virtualidade das representações; Britto, Mokarzel e Corradi entendem que assemelha-se à memória humana, mas em um intrínseco movimento desordenado que alarga os riscos de esquecimento; e para Silva, são as informações e conteúdos produzidos e arquivados em recursos de armazenamento digital, como aplicativos, blocos de notas e armazenamento em nuvem.

Em seguida, patrimônio digital aparece como termo recorrente, sendo compreendido entre os autores Ferreira e Rocha como bens culturais disponibilizados em ambiente colaborativo da web, promovendo assim a contínua circulação e difusão; para Jorente, Silva e Pimenta, são bens culturais criados somente no ambiente virtual ou por bens duplicados na representação da web; Mello, Luz, Montijano e Andrade, como constituído por fragmentos informacionais na internet; Rozestraten, Lima, Marques e Ferreira entendem como documentos físicos e virtuais disponibilizados em um ambiente colaborativo; e para Padilha, Café e Silva, são acervos físicos duplicados para o meio digital.

$\mathrm{Na}$ sequência, o termo memória virtual é o que apresenta maior convergência conceitual entre os autores, é compreendido por Damin, Dodebei, Morigi e Massoni como memória constituída pelas representações originadas a partir dos imaginários criados no espaço urbano e em seus elementos; Massoni e Morigi, construída pelas narrativas criadas nos ambientes virtuais e 
reproduzidas em permanentes conexões e reconexões com o passado ou objetos que se reconstroem em contínuo movimento e que formam o estoque informacional armazenado no ciberespaço. Contudo, o termo memória virtual apresenta a maior quantidade de termos e expressões associados ao âmbito virtual (20), seguido por memória digital, com 11. Já o termo patrimônio digital, também no âmbito digital, apresenta cinco termos e expressões associados, enquanto patrimônio virtual possui dois e amnésia digital, um.

\section{CONSIDERAÇÕES FINAIS}

Com base nos resultados obtidos, foram identificados e mapeados os autores que pesquisam virtualização da memória na Ciência da Informação brasileira e os termos e expressões utilizados por esses autores, o que possibilitou perceber a relação entre os termos e conceitos nos contextos textuais em que são utilizados. As análises dos textos foram essenciais para a caracterização dos termos e expressões utilizados pelos autores e também para perceber as aproximações e distanciamentos conceituais, cujo entendimento pode ser influenciado pelos contextos em que são desenvolvidos.

Dentre os termos, destacam-se memória digital, patrimônio digital e memória virtual. Com predominância de ocorrências, a memória digital apresenta conceitos distintos, possivelmente pelo fato de ser entendida como qualquer informação em meio digital ou também qualquer coisa que circula no ambiente virtual. Empregado amplamente, observa-se que existe entre alguns autores a preocupação em se buscar um conceito mais definido. Já patrimônio digital apresenta aproximações entre os autores e é compreendido como bens culturais produzidos em ambiente digital ou bens digitalizados.

A memória virtual, com maior incidência de termos associados, também apresenta convergência conceitual entre os autores. Abarcada como informação compartilhada no ambiente virtual, se caracteriza por ser constituída de fluxos informacionais incessantes, em permanente transformação e aberta ao processo lembrar-esquecer. Por estar associada às tecnologias de comunicação, a memória virtual existe a partir da memória digital. Nestas incongruências conceituais, percebe-se que, enquanto alguns autores compreendem que 0 
compartilhamento ou a publicação de informações em meio virtual já configura a memória virtual, outros destacam que, para haver memória virtual, é fundamental que haja interações. Caso contrário, tem-se apenas uma base de dados.

Percebe-se que, com as aceleradas transformações provocadas pelas TIC e pelo ciberespaço ser um ambiente caracterizado pela desterritorialidade e pelo contínuo movimento, discute-se os desafios atuais de se preservar as memórias digitais e virtuais. Com isso, apresentam problemáticas oriundas da preservação digital, por compreenderem que as discussões acadêmicas ainda não abrangem de forma eficaz as complexas representações virtualizadas e constantemente ressignificadas. Entre os aspectos evidenciados, as tensões geradas pelos processos lembrar-esquecer, que se assemelham à memória biológica (humana), se afirmam em posições de contraesquecimento e se contrapõem às questões concernentes ao direito à informação e ao direito ao esquecimento.

Observa-se que os termos e expressões originados na relação da memória com os ambientes virtuais e digitais correlacionam-se aos tradicionais fluxos que ocorrem no contexto físico: armazenamento, preservação, guarda, salvaguarda, registro, circulação, acesso, conservação, o que confirma a preocupação dos autores com o registro e a disseminação do conhecimento. A partir dessas questões observadas, infere-se que estudos assim são importantes para compreender o panorama do estado da arte das conceituações e contextualizações relacionadas à virtualização da memória e, nessa investigação, foi possível evidenciar as mais recentes contribuições da Ciência da Informação para essa discussão.

Agradecimentos - A pesquisa obteve o financiamento da Coordenação de Aperfeiçoamento de Pessoal de Nível Superior (Capes).

\section{REFERÊNCIAS}

CASALEGNO, F. Uma abordagem ecológica da memória em rede. In:

CASALEGNO, F. Memória cotidiana: comunidades e comunicação da era das redes. Porto Alegre: Sulina, 2006. p. 19-33. 
DODEBEI, V. Patrimônio digital virtual: herança, documento e informação. In: REUNIÃO BRASILEIRA DE ANTROPOLOGIA, 26., 2008, Porto Seguro. Anais [...], São Paulo: Associação Brasileira de Antropologia, 2008, p. 1 -12.

DODEBEI, V. Patrimônio e memória digital. Morpheus, Rio de Janeiro, v. 5, n. 8, 2006.

GONDAR, J. Por que memória social?. Morpheus, Rio de Janeiro, v. 9, n. 15, 2016.

HALBWACHS, M. Les cadres sociaux de la mémoire. Paris: Les Presses Universitaires de France, 1952.

HALBWACHS, M. Memória coletiva e memória individual. In: HALBWACHS, M. Memória coletiva. São Paulo: Vértice, 1990. p. 18-52.

LAZZARIN, F. A.; NETTO, C. X. A.; SOUSA, M. R. F. Informação, memória e ciberespaço: considerações preliminares no campo da Ciência da Informação no Brasil. Transinformação, Campinas, v. 27, n. 1, 2015, p. 21-30.

LÉVY, P. O que é o virtual? São Paulo: Editora 34, 2003.

MANGAN, P. K. V. Construção de memórias digitais virtuais no ciberespaço. In: FRANÇA, M. C. C. C.; LOPES, C. G.; BERND, Z. (Org.). Patrimônios memoriais: identidades, práticas sociais e cibercultura. Porto Alegre: Movimento, 2010. p. 170-184.

MONTEIRO, S.; CARELLI, A.; PICKLER, M. E. Representação e memória no ciberespaço. Ciência da Informação, Rio de Janeiro, v. 35, n. 3, 2006.

NORA, P. Entre memória e história: a problemática dos lugares. Projeto História, São Paulo, v. 10, p. 7-28, dez. 1993.

OLIVEIRA, E. B. O conceito de memória na ciência da informação no Brasil: uma análise da produção científica dos programas de pós-graduação. 2010. 194 f. il. Tese (Doutorado em Ciência da Informação) - Universidade de Brasília, Brasília, 2010.

\title{
MEMORY VIRTUALIZATION IN THE BRAZILIAN INFORMATION SCIENCE
}

\begin{abstract}
Introduction: based on reflections on the use of different terms and concepts attributed to memory in virtual and digital environments, it observes that memory has been reconfigured by new sociocultural practices that society develops in its communicative processes, in an incessant information flow that deterritorializes and resignify the memory. Objective: understand how the memory virtualization in the Brazilian
\end{abstract}


Information Science is studied. Methodology: qualitative and bibliographic study in the Reference Database of Periodicals Articles in Information Science. It identifies and maps the authors and the terms, expressions and definitions used by them when referring to memory in virtual and digital environments. It analyzes the relationship between terms and concepts, in order to show how the authors appropriate these concepts. Results: among the terms, digital memory, digital heritage and virtual memory stand out. Conclusions: even presenting conceptual incongruities, the discussions revolve around the challenges of preserving digital and virtual memories.

Descriptors: Information Science. Memory Virtualization. Digital Memory. Virtual Memory. Digital Heritage.

\title{
VIRTUALIZACIÓN DE LA MEMORIA EN LA CIENCIA DE LA INFORMACIÓN BRASILEÑA
}

\begin{abstract}
RESUMEN
Introducción: originada a partir de reflexiones sobre el uso de distintos términos y conceptos atribuidos a la memoria en entornos virtuales y digitales, señala que la memoria ha sido reconfigurada por nuevas prácticas socioculturales que la sociedad desarrolla en sus procesos comunicativos, en un flujo incesante de información que desterritorializa y resignifica la memoria. Objetivo: comprender cómo se estudia la virtualización de la memoria en la ciencia de la información brasileña. Metodología: estudio cualitativo y bibliográfico en la Base de Datos Referencial de Revistas de Ciencias de la Información. Identifica y mapea a los autores y los términos, expresiones y definiciones que usan cuando se refieren a la memoria en entornos virtuales y digitales. Analiza la relación entre términos y conceptos para resaltar cómo los autores se apropian de estos conceptos. Resultados: entre los términos, destacan la memoria digital, el patrimonio digital y la memoria virtual. Conclusiones: incluso con incongruencias conceptuales, las discusiones rondan los desafíos de preservar los recuerdos digitales y virtuales.
\end{abstract}

Descriptores: Ciencia de la Información. Virtualización de la Memoria. Memoria Digital. Memoria Virtual. Patrimonio Digital.

Recebido em: 02.11 .2019

Aceito em: 20.04.2020 